\title{
Conflicting Priorities in Social Legislation and Medicine: Gynaeco-oncology Patients and their Right to Participate in Society
}

\section{Im Spannungsfeld von Sozialgesetzgebung und Medizin: gynäkoonkologische Patientinnen und ihr Recht auf Teilhabe in der Gesellschaft}

Authors

Affiliations
E. Simoes $^{1,2,3}$, J. Graf ${ }^{1,2}$, D. Wallwiener ${ }^{1}$, S. Brucker ${ }^{1,2}$

${ }^{1}$ Universitätsfrauenklinik, Department für Frauengesundheit des Universitätsklinikums Tübingen, Tübingen

${ }^{2}$ Forschungsinstitut für Frauengesundheit, Department für Frauengesundheit des Universitätsklinikums Tübingen, Tübingen

${ }^{3}$ Stabstelle Sozialmedizin des Universitätsklinikums Tübingen, Tübingen

\section{Key words}

- participation

- severe disability

- gynaeco-oncology

- social legislation

Schlüsselwörter

- Teilhabe

- Schwerbehinderung

- Gynäkoonkologie

- Sozialgesetzgebung

Deutsche Version unter: www.thieme-connect.de/ ejournals/gebfra

\section{received 27.3.2015 \\ revised 20.7.2015 \\ accepted $\quad$ 8.8.2015}

\section{Bibliography}

DOI http://dx.doi.org/

10.1055/s-0035-1558055

Geburtsh Frauenheilk 2015; 75 :

1069-1074 @ Georg Thieme

Verlag KG Stuttgart · New York ISSN 0016-5751

\section{Correspondence \\ Joachim Graf, M. A}

Universitätsklinik Tübingen

Universitätsfrauenklinik,

Department für

Frauengesundheit

Calwerstraße 7

72076 Tübingen

joachim.graf@

med.uni-tuebingen.de

\section{Abstract \\ $\nabla$}

Due to the declining mortality rates, malignant diseases have gained a chronic character for many gynaeco-oncology patients. The patients can expect to participate in social life and to an increasing extent in professional life for longer lengths of time. Promotion of rehabilitation and participation is an issue of the German 9th Social Security Code that explicitly places a focus on women. This is mainly of relevance for tumour patients with regard to assessment of the degree of severe disability, to compensate for disease-induced impairments and the possibilities for improving the participation of the afflicted subjects, especially by means of protective rights in professional life. Indeed, tumour patients do sometimes find themselves confronted with conflicting priorities between the entitlements guaranteed by social legislation and the compensation conferred by the health-care services, which can then be avoided when the facts are sufficiently known. For this purpose, the physician must be fully aware of the legal situation. The present article provides an overview of the procedures and reference points for appraisals. Patients need partners among their responsible physicians to help in the assertion of their claims. From the physician's side it is necessary to classify the reported complaints within the ever increasing knowledge about the direct side effects and the long-term side effects of cancer therapies. Against the background of an often life-long mental stress and the uncertain risk of recurrence, it should also be considered whether the concept of healing probation is in support of the targets of long-term disease management and social reintegration, also in the interest of society in general.

\section{Zusammenfassung \\ $\nabla$}

Für viele gynäkoonkologische Patientinnen hat durch sinkende Mortalitätsraten die maligne Erkrankung einen chronischen Charakter erhalten. Die Patientinnen können langfristig am gesellschaftlichen und zunehmend auch beruflichen Leben teilhaben. Rehabilitation und Teilhabe zu fördern, ist Anliegen des Neunten Sozialgesetzbuchs, das ausdrücklich einen Fokus auf Frauen richtet. Es ist bei Tumorpatientinnen zumeist dann von Relevanz, wenn es um die Feststellung der Schwerbehinderteneigenschaft geht, um krankheitsinduzierte Benachteiligungen auszugleichen und die Teilhabemöglichkeiten der Betroffenen, besonders durch Schutzrechte im Arbeitsleben, zu verbessern. Tatsächlich befinden sich Tumorpatientinnen zuweilen in einem Spannungsfeld zwischen qua Sozialgesetzgebung garantierten Ansprüchen und den ihnen versorgungsmedizinisch erteilten Ausgleichen, was bei guter Kenntnis der Sachlage vermieden werden könnte. Dazu ist auf ärztlicher Seite Wissen zu den gesetzlichen Reglungen wichtig. Diese Übersicht gibt Einblicke in das Verfahren und Anhaltspunkte für Begutachtungen. Patientinnen benötigen Partner in den Reihen ihrer behandelnden Ärzte beim Geltendmachen ihrer Anliegen. Es gilt, ärztlicherseits die kommunizierten Beschwerden in das immer weiter wachsende Wissen um Nach- und Langzeitnebenwirkungen der Krebstherapie einzuordnen. Vor dem Hintergrund einer häufig lebenslangen psychischen Belastung und dem unbestimmten Risiko eines Rezidivs sollte zudem überdacht werden, ob das Konzept der Heilungsbewährung den Zielsetzungen gerecht wird, der langfristigen Krankheitsbewältigung und der sozialen Reintegration, auch im Interesse der Gesellschaft, Vorschub zu leisten. 


\section{Background

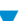

Not infrequently, patients are confronted with the opinion that to apply for a disabled person's pass is equated with a lack of will to get better. Patients report that they feel left alone by all sides when concerned with issues such as support to compensate for disease-related disadvantages and limitations and disputes with administrative authorities. It is the intention and mission of the 9th Social Security Code to promote rehabilitation and participation. Here the legislation has explicitly placed a focus on women. This part of social legislation regularly plays a role in daily and clinical routine when the degree of disability has to be assessed. As a general rule this is also true for cancer diseases. In such cases and in the associated official appraisals a lack of knowledge and a lack of understanding often lead to disputes and hardships that could have been avoided by a good knowledge of the situation. This article is intended to firstly objectify the discussions about “disabled person's passes" that very often arise in doctor's practices, hospitals, between experts and in public authorities. At the same time, this article aims to promote the discussion as to whether the objectives of the legislation and the legitimate requests of the patients for support to compensate for disease-related disadvantages and limitations are fulfilled by the current practices. Finally, the question should be posed if and how these procedures can be changed so as to be friendlier for the female patients. This article is also aimed to promote the discussion as to what extent the current situation as it is laid down in legislation is useful or if it is in need of change.

\section{Self-Determination and Participation in the Life of Society \\ $\nabla$}

The 9th Social Security Code [Sozialgesetzbuch (SGB) IX] "rehabilitation and participation of disabled persons" (Rehabilitation und Teilhabe behinderter Menschen) came into force on 01.07.2001. It is aimed at the participation of disabled persons in the life of society and in professional life. Impairments should be avoided or as such compensated for. Specific emphasis is placed here on women: "hereby the special requirements of disabled women and children and those threatened by disability are to be taken into account". This clearly implies that particular requirements for women have been assumed and that these have to be taken into account for supporting measures. In § 1 SGB IX the legislation explicitly recognises that disabled persons or those people threatened by disability should receive support according to this code (and the benefit laws valid for the rehabilitation providers) in order to maintain their self-determination and equal participation in the life of society.

The legislator has formulated a further definition of disability ( Table 1). Already in the 2nd sentence of paragraph 2 the term "severely handicapped" appears whereby a grading is referred to. The wording of the law does not answer the question as to where this grading comes from. The degree of disability (DoD) is used as a measure for the

- physical,

- mental,

- emotional and

- social effects

of a functional impairment due to a damage to health within the scope of SGB IX. The DoD encompasses the effects of functional impairments on all aspects of life and not just limitations in pro-
Table 1 Extract from the 9th Social Security Code, definition of disability ( $\$ 2$ SGB IX).

1. A person is disabled when his/her bodily function, mental ability, or emotional health deviates with a high probability for more than 6 months from that of the typical age-matched condition and thus impairs his/her participation in the life of society. They are threatened with disability when an impairment is to be expected.

2. In the sense of part 2, a person is severely disabled when a grade of impairment of at least 50 is present and when he/she has a legal place of residence, a habitual abode or a working place in the sense of $\S 73$ within the jurisdiction of this code of law.

3. Disabled persons with a grade of impairment of less than 50 but at least 30 and for whom the other prerequisites of $\S 2$ apply are to be treated equally as severely disabled persons when, as a consequence of their disability and without equal treatment, they are unable to obtain or retain an appropriate working place in the sense of $\S 73$ (equivalent disabled persons).

fessional life. This concerns the participation in "life of the society". The degree of disability should be assessed according to uniform principles and should be reported in grades of 10 up to a maximum of 100. (However, it is not a percent scale.) The law itself does not assign these grades to a specific disability. There are instructions for this in the medical health-care regulations (Versorgungsmedizin-Verordnung), specifically in the medical health-care principles (Versorgungsmedizinische Grundsätze), appended as attachment to $\S 2$ of the medical health-care regulations [1]. The medical health-care regulations are intended, as stated in the foreword, to ensure that "appropriate, faultless and for identical situations always uniform, evaluations ... for every single person entitled to maintenance and/or disabled, fair administrative decisions ..." are made. The medical health-care regulations and medical health-care principles are in the public domain and can be accessed under various internet addresses (e.g., http://www.gesetze-im-internet.de/versmedv/BJNR241200008. html).

\section{Medical Health-Care Principles \\ $\nabla$}

A glance at these compilations is worthwhile not only from the view point of preparing an expertise. The "medical health-care principles" have been in force since 01.01.2009 and are considered as reference points for medical expertise in social compensation law. The appendix to $\S 2$ of the medical health-care regulations consists of 4 parts:

- general principles (part A),

- DoD tables (part B),

- appraisals in social compensation law (part C) and

- markers or codes (part D).

Above all, the tabulations in part B provide experts with reference points as to what degree of disability can lead to specific health impairments in the sense of the medical health-care regulations.

This will now be demonstrated for the example of mastectomy ( Table 2). After plastic surgery to reconstruct the breast with autologous tissue, lower DoD values may be considered in cases with favourable surgical results. However, if unfavourable effects occur, for example, painful scar formation, such health impairments must be assessed additionally. Exceptional results or accompanying symptoms of the treatment - e.g., long-lasting, severe effects of repeated chemotherapy - need special consideration. It is important that all functional impairments be reported 
in the expertise and be charged for. Thus, for example, functional limitations in the shoulder girdle, the arm, the spinal column as consequences of surgery or radiotherapy (e.g., lymph oedema, muscular defects, nerve lesions, abnormal posture) as well as unusual psychotropic disorders should also be taken into consideration if necessary ( Table 3 ). For determination of the DoD, the loss of performance rather than the nature of the disease is decisive. Accordingly, the statements on other organ systems should be consulted and the appraisals listed there be taken into consideration: e.g., in the case of restricted thorax mobility due to extensive scar formation after radical mastectomy or pulmonary fibrosis after radiotherapy with reduced cardiopulmonary capacity: diseases of the heart, impairments of cardiac output, ... loss of performance already in mild burdens of daily life (e.g., walking [3-4 km/h], climbing one flight of stairs, mild physical work), complaints and occurrence of pathological values on an ergometer at 50 watts (at least 2 minutes); ... DoD 50-70. Another example is the chronic fatigue syndrome (CFS) that is listed in the section Fibromyalgia (section 18.4) with further syndromes, providing that this is "to be assessed analogously according to the functional effects". A judgement of the Federal Social Court elucidates the intention of the legislature that impairments that do not occur in all cases should be considered separately:

- Federal Social Court - B 9 SB 4/08 R - judgement of 30.09.2009: Loss of the thyroid gland after cancer disease without lymph node involvement is to be assessed with a DoD of 50 for the first 5 years. During the phase of healing probation (see below) this DoD 50 does not include impairments due to voice disorders because of vocal cord paralysis and persisting hoarseness, that occur at most in only $20 \%$ of the cases. Accordingly the DoD of 30 provided for this situation is to be additionally considered.

\section{Procedures to Determine (Severe) Disability}

From the physician's point of view it is important to know the process sequence. This is necessary in order to recognise the value of enquiries and appraisals and to be able to estimate the significance of one's own expert statements for the procedure. Again and again administrative decisions are made that are incomprehensible to both patient and physician. How does the procedure to determine a severe disability work ${ }^{1}$

The determination is undertaken on application to an appropriate authority, e.g., district administration, pension office (addresses can be obtained from, e.g. the mayor's office) - informally or by using an application form. Medical documentation can (but at first need not) be attached. When pertinent documentation is attached it may speed up the procedure. If the documentation demonstrates unequivocally, for example, the presence of a malignant breast cancer with definition of its stage, the patient will receive notification from the authority that must contain (according to $\S 35$ SGB X) at least the following:

- what disability (in the sense of the law) is present,

value of the DoD,

- markers (if relevant, see below.),

- additional "healing probation" (if relevant, see below), with details of the period presumably needed for the healing probation,

\footnotetext{
${ }^{1}$ For more details see, e.g., http://www.vdk.de/deutschland/pages/themen/ behinderung/9196/der_schwerbehindertenausweis
}

Table 2 Extract from the appendix to $\S 2$ of the medical health-care regulations.

\begin{tabular}{|c|c|}
\hline Mastectomy & DoD \\
\hline Unilateral & 30 \\
\hline Bilateral & 40 \\
\hline Segment or quadrant resection of the breast & $0-20$ \\
\hline $\begin{array}{l}\text { Healing probation in case of malignant regeneration } \\
\text { of the mammary gland }\end{array}$ & \\
\hline $\begin{array}{l}\text { After removal of a carcinoma in situ of the mammary gland, } \\
\text { a healing probation is to be awaited in the first } 2 \text { years. } \\
\text { The DoD during this period is } 50 \text {. } \\
\text { After removal of a malignant tumour of the mammary gland, } \\
\text { a healing probation is to be awaited in the first } 2 \text { years. }\end{array}$ & \\
\hline DoD during this period & \\
\hline - for removal in stage (T1 to T2) pNO M0 & 50 \\
\hline - for removal in stage (T1 to T2) pN1 M0 & 60 \\
\hline in higher stages at least & 80 \\
\hline $\begin{array}{l}\text { If the effects of the operation and any necessary treatment } \\
\text { measures give rise to a DoSD of } 50 \text { or more, the DoD to be applied } \\
\text { during the healing probation should correspondingly be higher. }\end{array}$ & \\
\hline
\end{tabular}

Table 3 Extract from the appendix to $\S 2$ of the medical health-care regulations, injury to the upper extremities.

Stiffening of the shoulder joint in a favourable position with
good mobility of the shoulder girdle
Stiffening of the shoulder joint in a spreading angle of ca. $45^{\circ}$
and slight suspension is considered to be functionally favourable.
Stiffening of the shoulder joint in an unfavourable position
or impaired mobility of the shoulder girdle
Limited mobility of the shoulder joint (including shoulder girdle)
Arm lifting up to $120^{\circ}$ with corresponding restriction of rotating
and spreading ability
$\begin{aligned} & \text { Arm lifting up to } 90^{\circ} \text { with corresponding restriction of rotating } \\ & \text { and spreading ability }\end{aligned}$

- notification that the responsible authority will take action after the stated period in order to check whether the decision will still be valid.

If the state of health should change markedly (better or poorer), the holder of a disabled person's card is obliged to inform the pension office accordingly so that, if necessary, the DoD and the markers can be reassessed appropriately. The disabled person's card is valid for at the most 5 years. On expiry it can be renewed without any particular formalities at the responsible pension office, often also at the community mayor's office.

\section{Avoiding or Counteracting Disadvantages \\ $\nabla$}

As a result of the severe disability, the patient acquires the rights to support that is intended to promote "self-determination and equality of participation in the life of society and to avoid or to counteract disadvantages". These supporting measures and rights should compensate for the disadvantages that arise directly from the disability ( $\$ 1$ SGB IX). The intended compensation measures involve various aspects of life. A few examples will be mentioned here. At the top of the list one should mention protective rights with regard to the working place ( Table 4): because oncological diseases, e.g., breast cancer, have in the mean- 
Table 4 Protective rights according to SGB IX with regard to the working place.

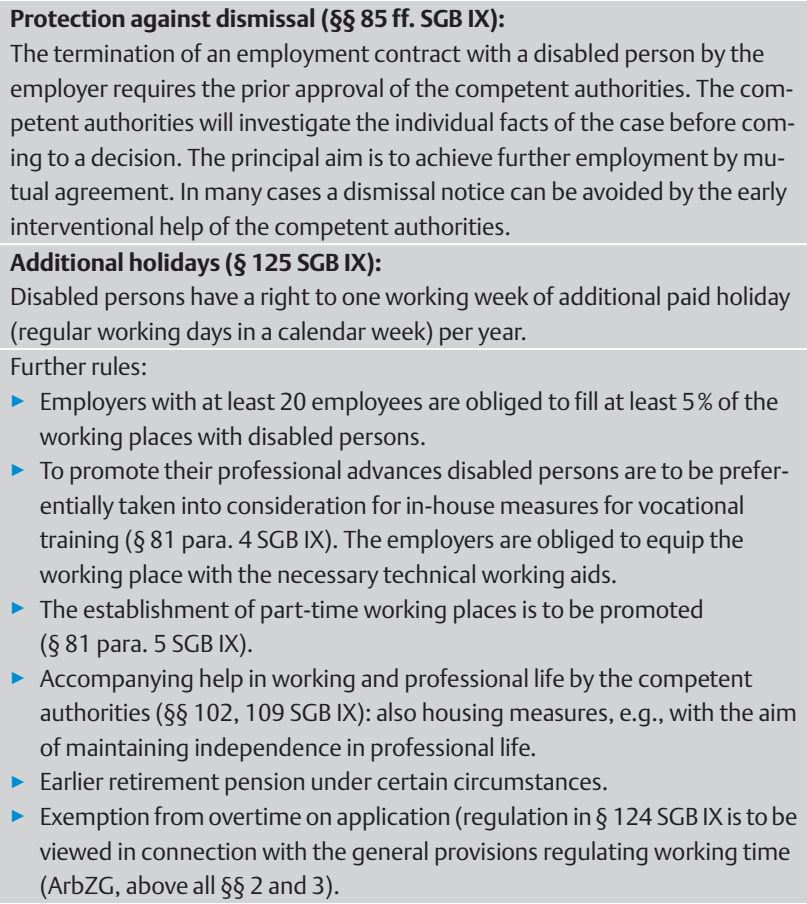

time gained the character of a chronic disease [2] and a return to the working place occur increasingly often in the course of the patient's life, these protective rights are of particular importance. Many patients also consider this to be of the highest importance. Conversations with patients have shown that the risk potential to lose one's job is high after a breast cancer operation, and that it is very difficult thereafter - as cancer patient - to find a suitable new professional occupation. Accordingly, the protection of an existing working place is rightly given a high relevance by the legislation. But, also from a (social) medical point of view, and in the light of social rehabilitation of patients as well as knowledge of the health-promoting value of a stable environment for a comprehensive convalescence process [3], the professional security of the patients is of major relevance. In addition there are the negative health consequences of (long-term) unemployment. At this point the option for stepwise reintegration should be explicitly mentioned, this serves for a reintroduction in the working processes over a period of up to 6 months depending of the patient's abilities and health situation. The stipulations for this can be found in the work incapacity guidelines (https://www.g-ba.de/ informationen/richtlinien/2/). This valuable tool is used much too infrequently. The treating physicians recommend the time course and stepwise increases in load in a reintegration programme. Should the patient be unable in her performance capacity to follow the plan it can be adjusted at any time.

The tax allowance should also serve to compensate for disadvantages. because of the exceptional costs that can develop directly from his/her disability the disabled person can assert a claim for a handicapped persons allowance [4] instead of a tax reduction according to $\S 33$ EStG when the degree of disability amounts to at least 50. Discounts of varying sizes may be granted, e.g., for the purchase of a new car or for membership fees.

\section{Markers as Special Disadvantage Compensation}

$\nabla$

Markers are entered in the disabled person's card and identify particular impairments that are subject to special disadvantage compensations. Thus, for example, the marker aG - "severe walking impairment" allows car parking in specially designated places. The marker $\mathrm{H}$ is of special significance for the gynaecooncological and geriatric gynaecological fields: $\mathrm{H}$ - helpless person. Helplessness is to be assumed for a disabled person when, as a result of the disability, outside help is continuously required, not just temporarily, for a series of frequent and regularly recurring activities to ensure safety of personal existence in the course of everyday life. Also taken into account is what burdens are still acceptable in each individual case. In cases of care level 2 or 3 (according to SGB XI) it is assumed without closer inspection that the criteria for marker $\mathrm{H}$ are fulfilled as is also the case for, for example, severe visual impairments. The following compensations are applied in such cases: free use of public transport, exemption from vehicle tax, tax concessions, nursing allowances [5] etc.

\section{Healing Probation - What does it Mean? \\ $\nabla$}

The term healing probation addresses the question for what period the designation of a severely disabled condition should be valid in the case of cancer disease (e.g., breast cancer). It is not stated in the Social Security Code 9 itself but can be found in the medical health-care regulations. A healing probation must be awaited for all such diseases in which a treatment success cannot be estimated with certainty - e.g., after transplantation of internal organs, malignant tumours, alcohol diseases, etc. The term found its first use in connection with the clinical course following a cardiac infarction. For such diseases reference values for the DoD during the healing probation and the duration of the healing probation are given in the medical health-care principles. During this time a higher DoD is recognised than that derived for the existing impairment - to some extent as a type of "hazard flat rate". For this concrete impairments do not have to be claimed and justified. The beginning of the healing probation is the point in time when the tumour can be considered as being removed by surgery and/or radiotherapy and/or chemotherapy.

The duration, for example, in cases of breast cancer varies depending on the stage ( Table 2). After completion of the healing probation, the DoD is evaluated again. Provided that no recurrence can be detected a lower DoD will be assigned for the future. This is often also the case when the health status has not changed at all after completion of the healing probation because the evaluation concerns exclusively the remaining concrete functional impairments.

\section{After Completion of the Healing Probation: The Role of the Treating Gynaecologist in the Assessment $\nabla$}

As a rule, when provided by the corresponding administrative body ("decision-making body") it is mentioned that this body will also undertake the review. The decision-making body arranges a review by, e.g., inviting the disabled person to a public health check-up before completion of the healing probation and/or sends a questionnaire to the treating physician. These enquiries, mostly from the pension office, are in daily routine not always ascribed the importance that should be due to the policy- 
guiding nature of the answers in the procedure. If no concrete impairments are mentioned or, respectively, persisting health deficits are presented, and no recurrences, metastases have developed, the "hazard flat rate" (general assessment based on tumour status) is discounted while the markers are not inevitably dropped.

Since after the phase of healing probation a flat-rate measurement of the DoD follows, in the framework of which the individual remaining impairments and deficits are taken into consideration for the assessment, it is even more important that these be identified in a detailed conversation with the patient. From the physician's side, a knowledge of side effects (e.g., the later occurring side effects of drugs, chemotherapy and radiotherapy) facilitates the conversation [6,7]. Sensitivity disorders resulting from the neurotoxicity of chemotherapeutic agents that restrict the use of an extremity, hearing disorders, fatigue or "chemo brain" $[8,9]$ are additionally characteristic for the health impairments that can lead to permanent loss of organs after mastectomy (० Table 2).

Comments such as,

- "Sometimes I can barely concentrate on a conversation - I have difficulties in orientation and easily lose my way when driving",

- "Suddenly in the middle of a sentence I can no longer think of the right words",

- "I forget important things like birthdays and appointments" and

- "I am no longer as fast as I used to be" [10].

should be classified by physicians within the ever increasing knowledge about side effects and long-term side effects of cancer therapy. The "translation" in speech and rule books of social security legislation, e.g., in medical and expert opinions, makes it easier for the patient to enforce her claims (e.g., sensitivity disorders of the hands that impair the gripping and holding functions can, depending on the extent, correspond to a partial loss (of ability) of the limb. Cognitive and mental disorders, disorders of sexuality and anxiety disorders should be invoked separately, as also should complaints/deficits that at first are not associated or appear not to be associated with the cancer disease. When a different specialty is concerned, additional expertise should be encouraged if necessary.

The presentation of the impairments to health identified in cooperation with the patients in the systematics of the medical health-care regulations is extremely important for the administrative procedure for the new assignment of the degree of disability.

\section{The Hearing Prior to Notification}

\section{$\nabla$}

Fundamentally, the decision must be communicated in written form. Prior to the decision a hearing must at first have taken place since the rights of the afflicted person are encroached upon. The persons concerned must be informed in detail of the reasons that lead to the intended decision. The persons concerned can, in the framework of the hearing, invoke other facts of the matter (e.g., deterioration of complaints, newly occurring complaints). Provided that no other reasons are presented that speak against a reduction, the decision is made. The course of time itself is considered to be a major change in the sense of $\S 48$ SGB X (e.g., BSG judgement B 9 SB 6/02), wherefore a reduction follows even when nothing has changed in the patient's health status after, e.g., the mastectomy. An objection to the DoD lowering decision can be filed and also an appeal can be lodged in front of the social welfare court. When a DoD $<50$ is determined, the protective functions are dropped. ${ }^{2}$

\section{Points of Criticism and Discussion}

$\nabla$

The current legal frame works, the provisions of the medical health-care regulations and their implementation are topics of criticism and discussion from widely varying perspectives.

The aim to promote participation is very often thwarted by disputes about invoked claims and lack of recognition. Thus, patients experience a lack of recognition of their reported complaints, health deficits and consecutive symptoms in the administrative procedure. According to patient reports the frequent downgrading or, respectively, the high rejection rate of appeals is discouraging. A public transparency (e.g., statistical results) about the review practices of the pension administration does not exist. The patients also often complain of a lack of time, lack of competence or lack of interest in the consultation offices. The end of the healing probation is often experienced as an especially critical time point: "In our daily routine we again and again find that very many afflicted persons feel that they have been entirely abandoned at the end of the five-year period. After all they must continue to take drugs that, in part, are associated with considerable side effects" [11].

At the same time on the treating physician's side there are constraints that additionally hinder the assessment situation. The content-wise time-consuming assessments are not adequately reimbursed. In order to uncover the long-term effects of the disease, not infrequently a comprehensive, time-consuming "investigation" is necessary - not because the health/mental/psychosocial problems do not exists but rather because many patients consider in their self-perception that they want "somehow to be able to cope" with everything, which works against a demonstration of the complaints. If this is reported the medical classification in the systematics of the medical health-care regulations requires a very good knowledge of the latter. It is just as time-consuming when one has to communicate that the complaints cannot be properly depicted in this systematic. In addition, this is not always understandable for the patient.

In the light of this problematic assessment situation, even the legal community rightly considers that it should be discussed whether it would not be better, in cases of cancer diseases with a persisting risk of recurrence and the uncertainty about the course of the disease and taking into account the life-long mental stress, to provide a higher assessment of the DoD not just for the period of healing probation but permanently [12]. This would be equally advantageous for the medical profession, the subsequent legal disputes and, last but not least, the (health) situation of the patient.

Just the special protective effects for the working place are in many cases highly valued by patients with cancer but are then lost with the loss of the disabled person status. These protective

\footnotetext{
2 SGB IX, § 116, (1) The special regulations for severely disabled persons are no longer applicable after cessation of the prerequisites according to $\S 2$ para 2; when the degree of disability drops below 50 but only at the end of the third calendar month after the non-appealability of the degradation notification becomes final.
} 
effects also have a very high value from the medical point of view. If these women have to face the labour market without protection, they will often not be competitive due to restrictions imposed by their disease. The resulting (long-term) unemployment endangers not only the patients' quality of life but also their health and chances of survival. At the same time society loses the contribution from remaining competences which a participation to an appropriate extent would have made possible.

\section{Conclusions}

Against the background of

- the life-long persisting mental stress of cancer disease,

- the non-determinable risk for renewed disease for each individual,

- a risk for new or recurrent disease extending beyond the fiveyear period - formally defined as the time for "healing probation",

the committees of the professional organisations and societies should initiate at a national level discussions to promote a permanently higher assessment of the DoD for cancer patients. In the daily practice the procedure after completion of the healing probation phase needs to be paid more attention in the future. All too often standard formulations like "I can manage" are used to cover diverse bypass strategies due to appreciable deficits. The patients need a partner among the ranks of their treating physicians in the assertion of their claims and the rights assigned to them in the 9th Social Security Code. In particular, the protective rights with regard to the working place play a paramount role in the context of social reintegration and long-term coping with the disease.

\section{Conflict of Interest}

None.

\section{References}

1 Versorgungsmedizin-Verordnung. Online: z.B. http://vmg.vsbinfo.de/ oder www.gesetze-im-internet.de $\rightarrow$ Gesetze/Verordnungen $\rightarrow \mathrm{V} \rightarrow$ VersMedV $\rightarrow$ Anlage zu $\S 2 \rightarrow$ Anlagen; Stand: 25.03.2015

2 Tighe M, Molassiotis A, Morris J et al. Coping, meaning and symptom experience: a narrative approach to the overwhelming impacts of breast cancer in the first year following diagnosis. Eur J Oncol Nurs 2011; 15: 226-232

3 Nilsson B, Holmgren L, Stegmayr B et al. Sense of coherence - stability over time and relation to health, disease, and psychosocial changes in a general population: a longitudinal study. Scand J Public Health 2003; 31: 297-304

4 Sozialverband VdK Nordrhein-Westfalen e.V. Pauschbeträge für behinderte Menschen: Online: http://www.vdk.de/nrw/pages/sozialpolitik/ nachteilsausgleiche/13475/pauschbetraege_fuer_behinderte_ menschen; last access: 25.03.2015

5 Merkzeichen Schwerbehindertenausweis. Online: http://www. myhandicap.de/schwerbehinderten_merkzeichen.html; last access: 25.03.2015

$6 \mathrm{Yi} \mathrm{A}$, Kim HH, Shin HJ et al. Radiation-induced complications after breast cancer radiation therapy: a pictorial review of multimodality imaging findings. Korean J Radiol 2009; 10: 496-507

7 Petersen $C$, Würschmidt $F$. Late toxicity of radiotherapy. A problem of challenge for the radiation oncologist. Breast Care (Basel) 2011; 6: 369-374

8 Schagen SB, Das E, Vermeulen I. Information about chemotherapy-associated cognitive problems contributes to cognitive problems in cancer patients. Psychooncology 2012; 21: 1132-1135

9 Myers JS. Chemotherapy-related cognitive impairment: the breast cancer experience, a focus group. Oncol Nurs Forum 2012; 39: E31-E40

10 Munir F, Burrows J, Yarker J et al. Women's perceptions of chemotherapy-induced cognitive side affects on work ability: a focus group. J Clin Nurs 2010; 19: 1362-1370

11 Karin Meißler, stellvertretende Bundesvorsitzende der FSH. Online: http://www.frauenselbsthilfe.de/aktuelles-presse-2012/pressemitteilungen/unterschriftenaktion.html; last access: 25.03.2015

12 Dolata R. Der Begriff der Heilungsbewährung im Schwerbehindertenrecht. Behindertenrecht 2012; 5: 153-157 